\title{
The Impact of Meaning Expansion at Al-Safadi in The Interpretation of Kashif Al-Asrar Wa Hatik Al-Star - Verbs as A Model
}

\author{
Azhar Muadh Abdulaleem Alsaadi \\ Imam A'adhum University College, Baghdad, Iraq \\ abdulrahmansaadi1994@gmail.com
}

KEYWORDS: $\quad$ Expansion, Meanings, Safadi, Phrases, Verbs.

Crossref doi) https://doi.org/10.51345/.v32i3.293.g233

\begin{abstract}
:
The expansion of meaning in the linguistic connotation in general and the Qur'an in particular is broad and multifaceted, represented by the ability of a single word or phrase to bear the meanings of several in a single expression. The context of the text and its coordination with what is before and after it to find out the intended meaning, and Al-Safadi was aware of his linguistic taste in standing on the phenomenon (expansion of meaning) and turned in his mindset the interpretation of possible meanings according to what the context requires in the Qur'anic expression. In this research, I will discuss some of the expressions that Al-Safadi expands on the meaning of some of the verbs mentioned in the Holy Qur'an in the context of his interpretation of the Qur'anic verses. The research was divided into three demands: The first topic: Expanding the meaning of the past tense. The second topic: Expanding the meaning of the present verb. The third topic: Expanding the meaning of the verb command.
\end{abstract}




\title{
أثر التوسع المعنوي عند الصفدي في تفيسر كثف الأسرار وهتك الأستار (الأفعال إنموذجا)
}

\author{
أزهر معاذ عبد العليم السعدي

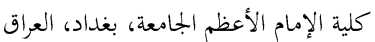 \\ abdulrahmansaadi1994@gmail.com
}

الكلمات المفتاحية التوسع، المعالي، الصفدي، الألفاظ، الأفعال.

Crossref doi) https://doi.org/10.51345/.v32i3.293.g233

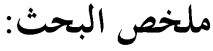

التوسع في المعنى في الدلالة اللغوية عموماً والقرآنية خصوصاً واسع متعدد الأوجه، يتمثل بقدرة اللفظ الواحد أو العبارة الواحدة على أن تحتمل معاني عدَّة في تعبير واحد، وهذا الجانب الذي تنبَّه إليه المفسرون في تفاسيرهم للفظة القرآنية، وكيفية توظيفها في تأويل المعاني العديدة في العبارة الواحدة بحسب سياق النص وتنسيقه بما قبله وما بعده للوقوف على المعنى المقصود، وتنبَّه الصفدي في ذائقته اللغوية في الوقوف على ظاهرة (التوسع في المعنى) وقلب في عقليته تأويل المعاني المحتملة بحسب ما يقتضيه السياق في التعبير القرآين. وسأتناول في هذا البحث بعض الألفاظ التي توسَّع ال صفدي في معنى بعض التئ الأفعال التي وردت في القرآن الكريم في معرض تفسيره للآيات القرآنيه. وقسمت البحث على ثلاثة مطالب وهي: المبحث الأول: التوسع في معنى الفعل الماضي. المبحث الثاني: التوسع في معنى الفعل المضارع. المبحث الثالث: التوسع في معنى فعل الأمر.

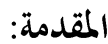

التوسع في اللغة: الواو والسين والعين: كلمة تدل على خلاف الضيق والعسر، يقال وسع الشيء واتسع. ووسع الشيء بالكسر يسعه سعة، أي: لا يضيق. و الله الواسع، أي: الغني.

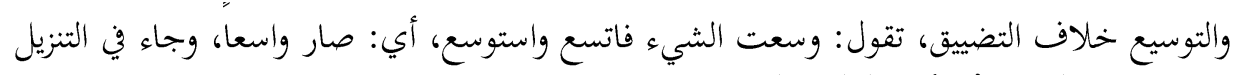

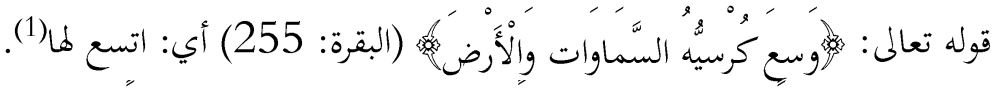

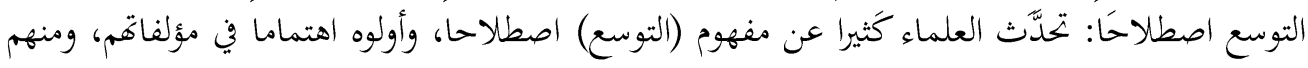

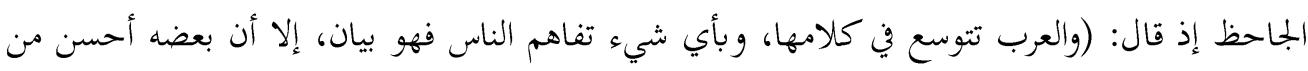

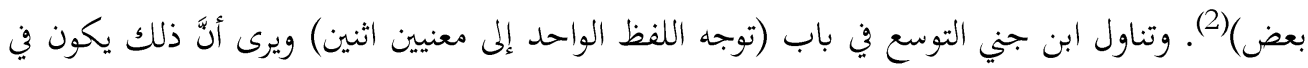

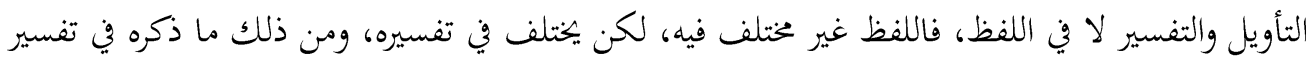
قوله تعالى: 
كثيرا، فمنهم من قال: أي هو أمر عظيم فإنما ينادى فيه الرجال والجلة لا الإماء والصبية، وقيل: أي ليس

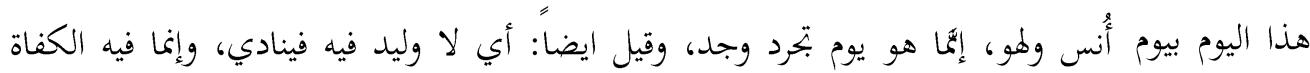

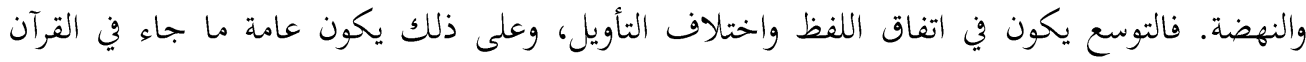

$$
\text { الكريم والحديث النبوي الشريف وكلام العرب شعراً ونثراً (3). }
$$

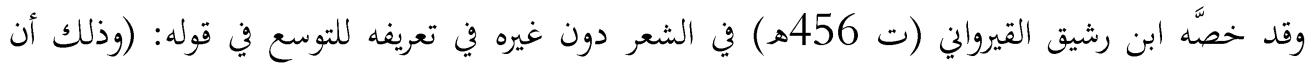

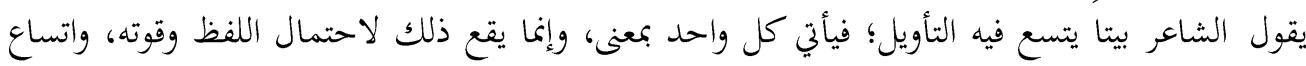
المعنى) وسمي التوسع ب(التوسيع)، ومن ذلك ما ذكره السبكي (ت 773 هـ ) في كتابه عروس الأفراح فقال: (وقد

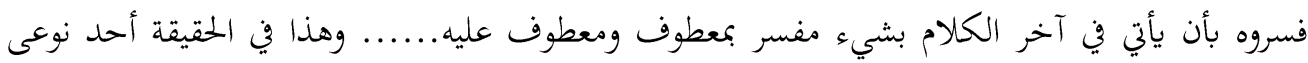
اللف والنشر)(5). وقد علَّ السيوطي ظاهرة (التوسع) من وجوه الإعجاز القرآني وذكر ذلك قائلا: (من أنوع معجزات القرآن

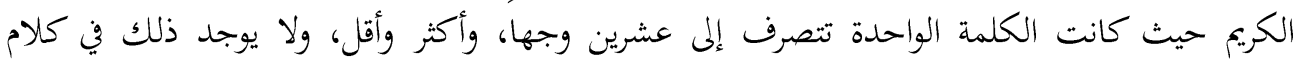

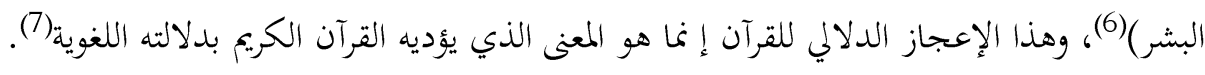

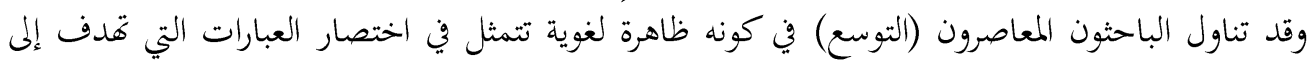

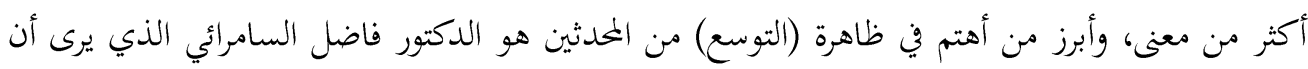

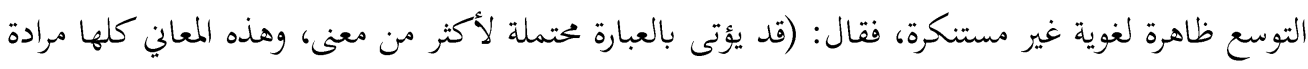

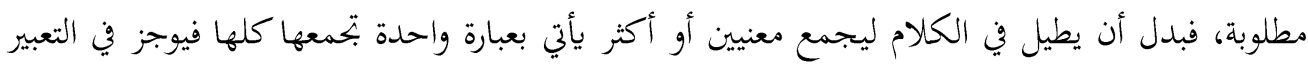
ويوسع في المعنى) (8).

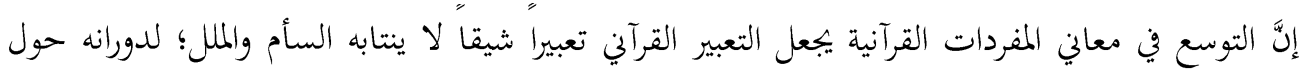

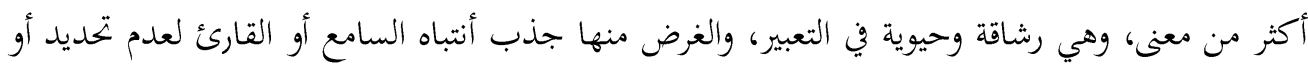

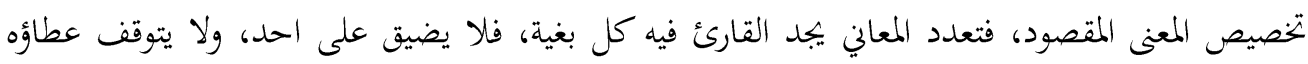

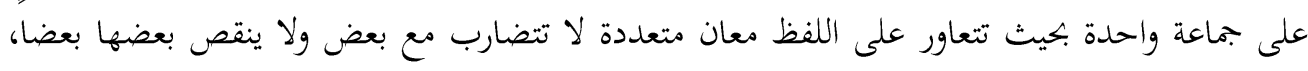

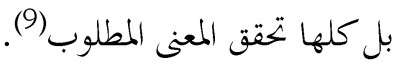
إن التوسع في معنى التعبير القرآين لا بد له من عوامل ومسوغات أدت إله إلى إمكانية احتمال اللفظ في العبارة

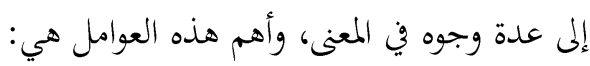


1. الألفاظ المشتركة: في العربية ألفاظ تشترك في معاني عديدة كالعين، والقرء، واليد، وهذه الألفاظ تأتي

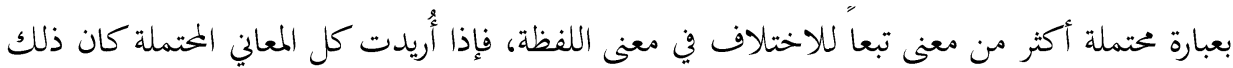
من التوسع في المعنى.

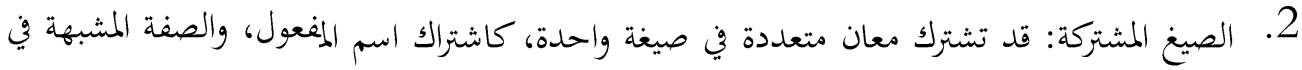

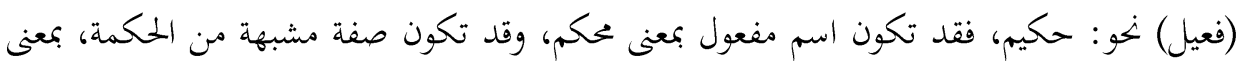

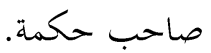
3. الجمع بين الألفاظ والصيغ ذات الدلالات المختلفة، وذلك نحو: (أعطيته عطاء حسناً)، فتأي بالفعل

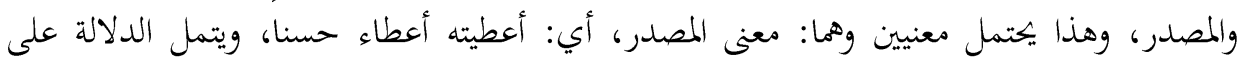

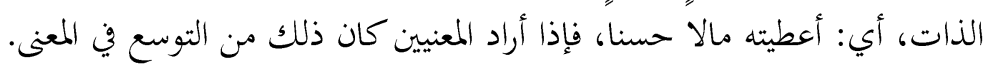

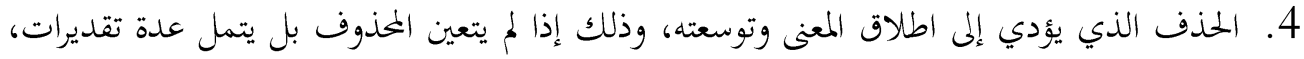

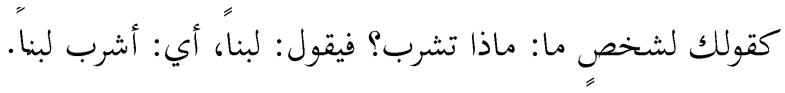

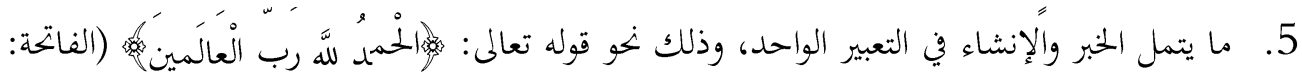

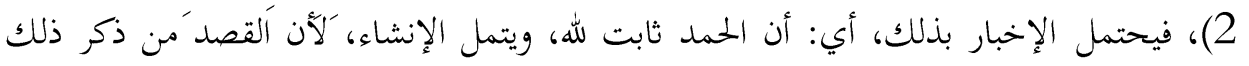
على سبيل المدح والتعظيم (10).

المبحث الأول: التوسع في معنى الفعل الماضي أولاً: التوسع في معنى (أخلَدَ)

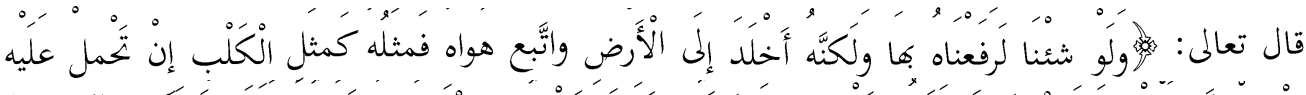

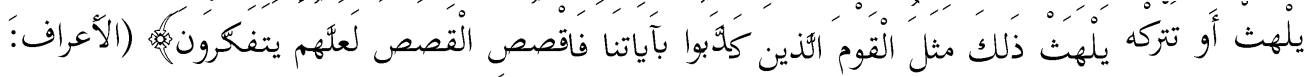

ذكر الصفدي بأن الفعل الماضي (أخلد) في الآية يحتمل معنيين، أحدهما: قيل بمعنى أطرق إلى الأرض، أي:

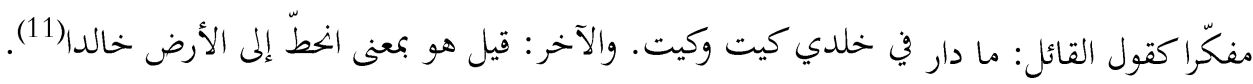

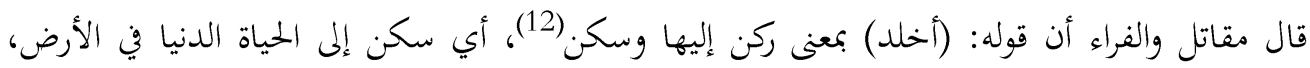

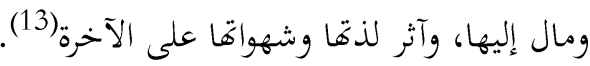

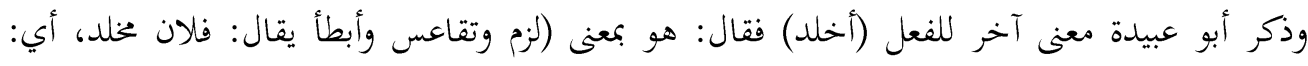

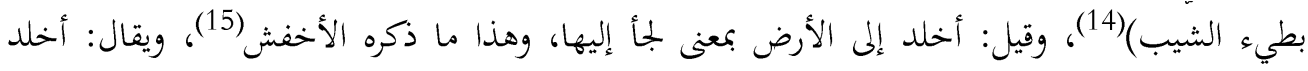


فلان إلى كذا وكذا، وخلد إلى كذا وكذا، ولكن أخلد أكثر في اللغة، والمعنى أنه مال وسكن إلى لذات الأرض، وهذا المعنى الغالب عند أكثر العلماء(16). ففي قوله أخلد إلى الأرض، تمتيل لحال المتلبس بالنقائص والكفر بعد الإيمان والتقوى بحال من كان مرتفعا

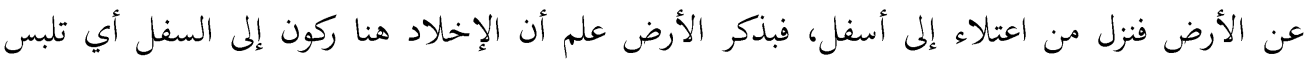

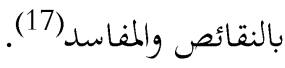

\section{ثانياً :التوسع في معنى (أسروّه)}

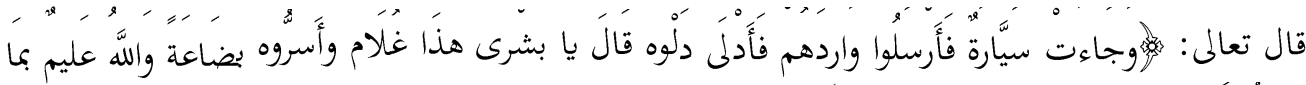

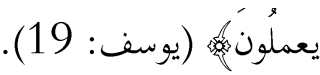
ذكر الصفدي في معرض تفسيره للآية معنيين للفعل (أسروهُه) إذ قال: (وأسروّهُ، من السر، أي: أخفوه في الطرقات لئلا يظهر أمره فيؤخذَ، وقد يكون بمعنى جعلوه بضاعة سرا بينهم وبين أنفسهم) (18).

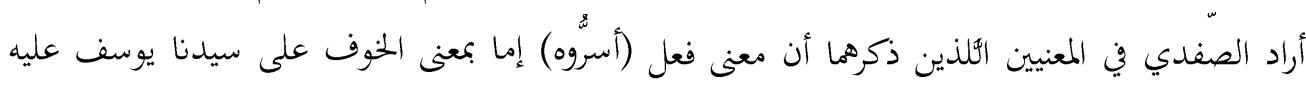
السلام أو بمعنى جعلوا أمر البضاعة خفية ليكون سراً بينهم.

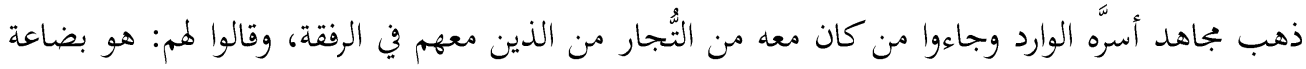

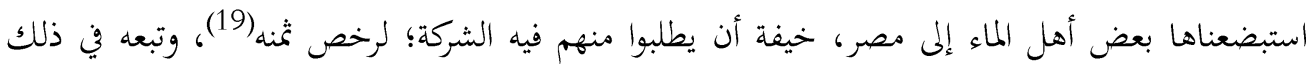

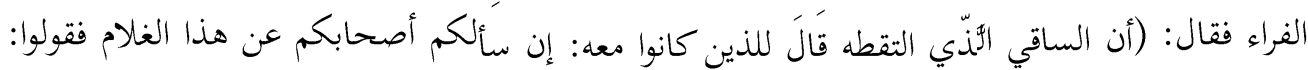

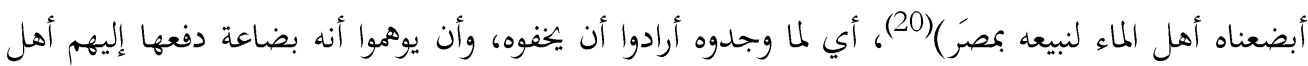

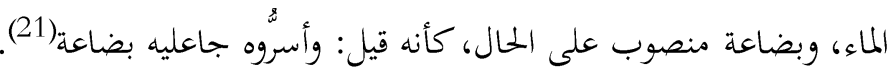

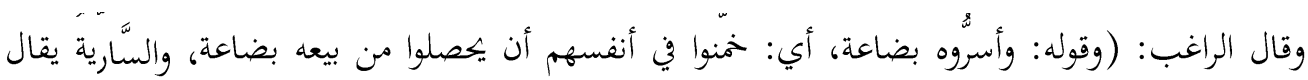

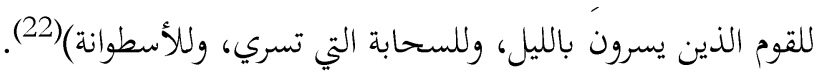

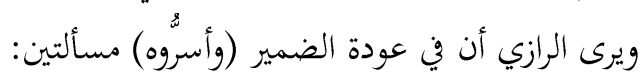

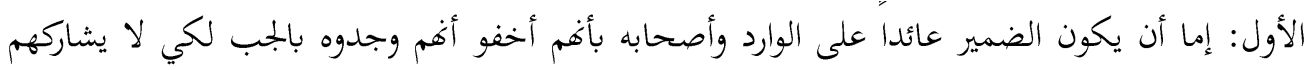

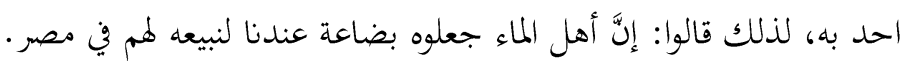

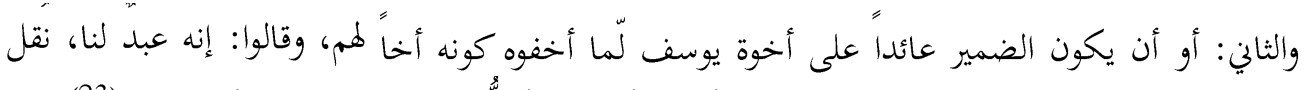

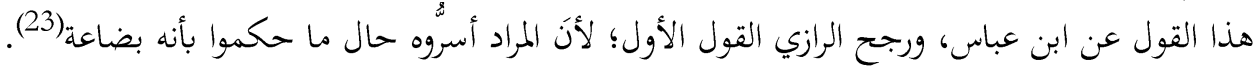


فلمراد من قوله: (وأسرُوهاه) هو الخوف من فقد يوسف قبل أن يبعوه، أي: تعاملوا مع الأمر بسرية وخفاء

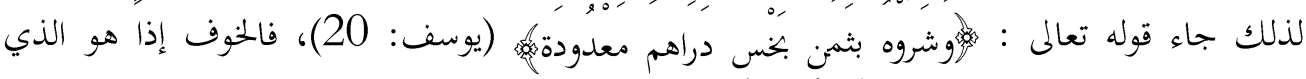

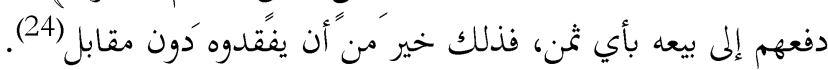

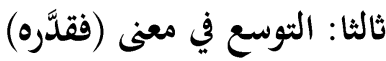

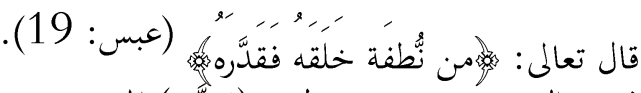

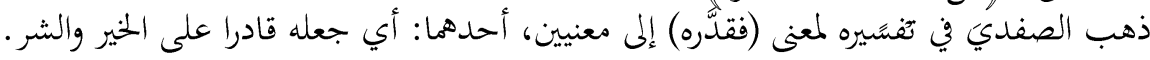

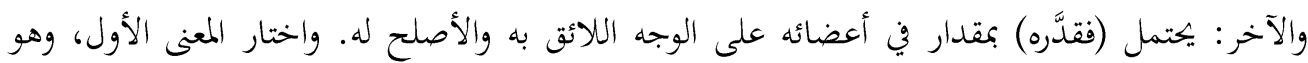

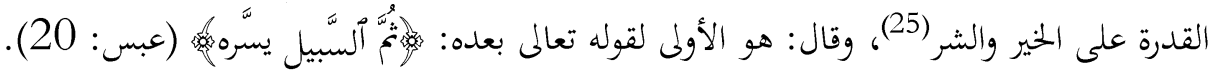

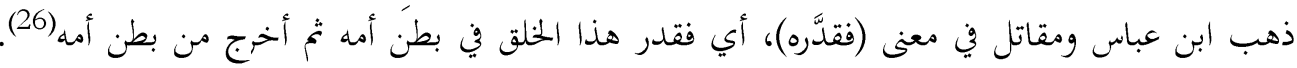

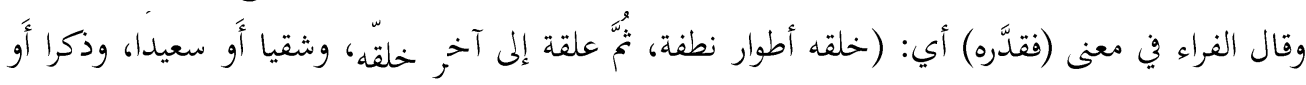
أنثى)

واهتدى الزجاج إلى معنى آخر للفعل (فقدَّره) فقال: (المعنى فقدره على الاستواء كما قال عز وجل:

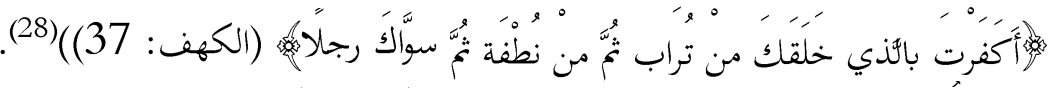

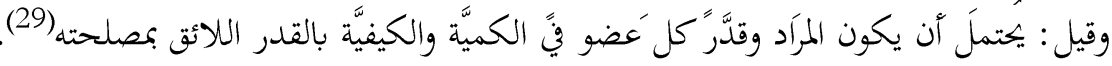

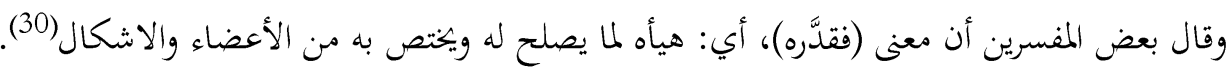

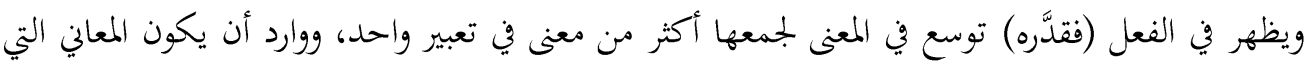

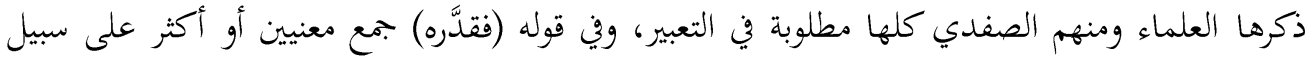
الإيضاح والإيجاز.

\section{رابعاً: التوسع في معنى (فتنوا)}

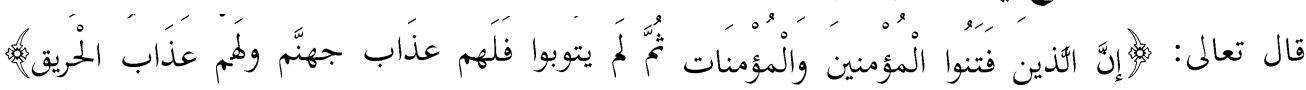

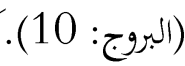
ذهب الصفدي في معنى الفعل (فتنوا) إلى تأويلين، إذ قال: (الفتنة ههنا يحتمل أنه أراد بها القتل، ويحتمل

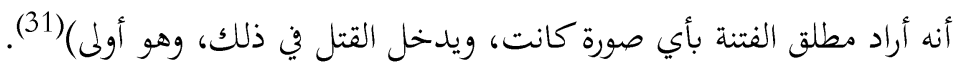

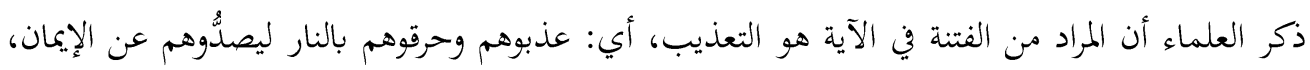

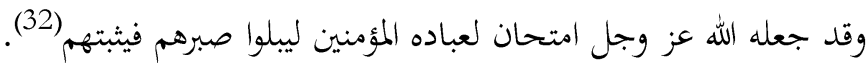


وقال الزجاج: (يقال: فتنت الشيء، أحرقته، والفتين حجارة سود كأفا محرقة)(33). والفتنة من الأفعال التي تكون من الله تعالى، ومن العبد كالبلية والمصيية، والقتل والعذاب، ومتحى كان من الله يكون على وجه الحكمة، ومتى كان من الإنسان بغير أمر الله يكون بضد ذلك. وتليه وتأتي الفتنة أيضا بمعنى

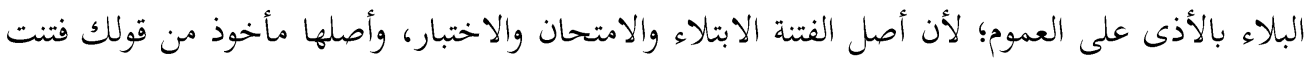

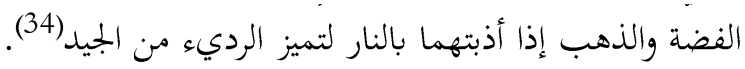
ويتبين مما سبق أن المعاني التي تناولها العلماء كلها تدل على أن معنى الفتنة في الآية يدل على الفيلى البلاء، وفي

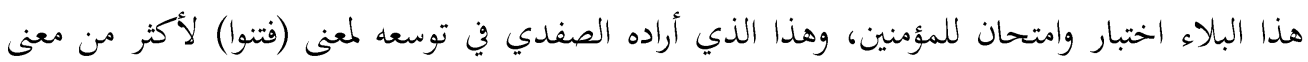

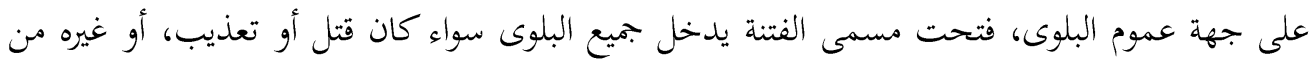

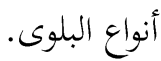

المبحث الثاني: التوسع في معنى الفعل المضارع أولاً: التوسع في معنى (ينظرون)

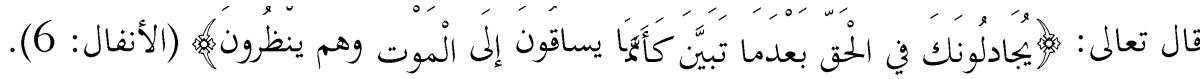

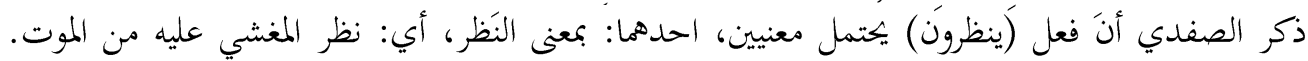
والآخر: بمعنى الانتظار، أي: انتظار ما وعدهم به من النصر عن الله تعالى، ورجح الصفدي هذا القول

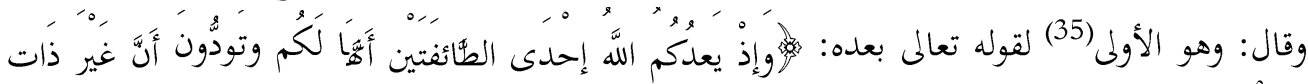

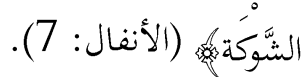
ذكر المفسرون أن (ينظرون) يعني النظر إلى القتل، لشدة كراهتهم للقتال كأفم يساقون عيانا إلى الموت، وهو

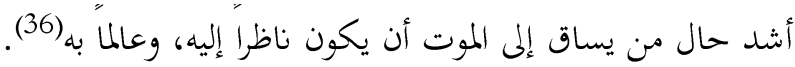

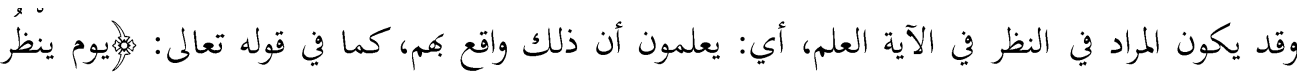

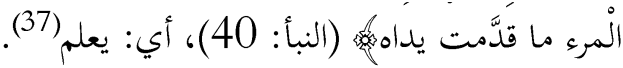
ويظهر مما سبق توسع الفعل (ينظرون) في الآية الكريمة، لأنه جمع أكثر من معنى في نفس العبارة، ولا مانع

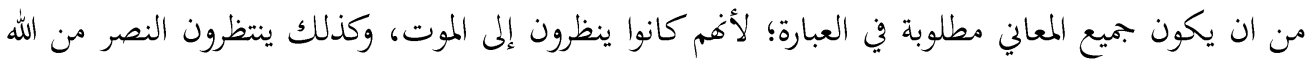
تعالى كما رجح الصفدي في تأويله. 


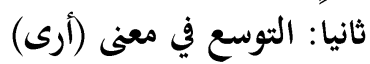

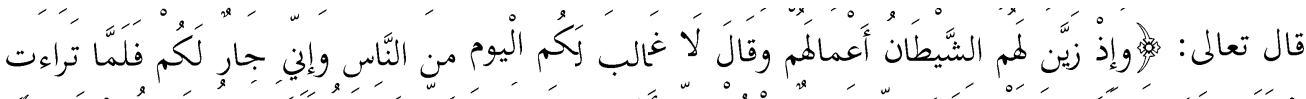

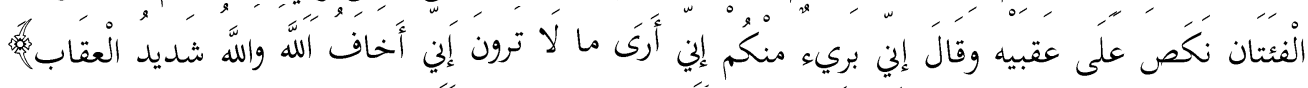

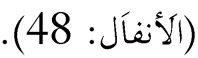

توسع الصفدي في معنى الرؤية في قوله تعالى: (أرى) إلى احتمالين، إذ قال: (يحتمل رؤية القلب، ويتتمل رؤية العين ويريد به رؤية الملائكة، فإن الشيطان يراهم دون الكفار والمان المؤمنين) (38).

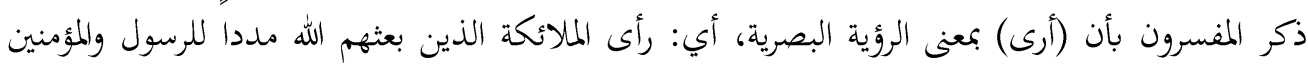

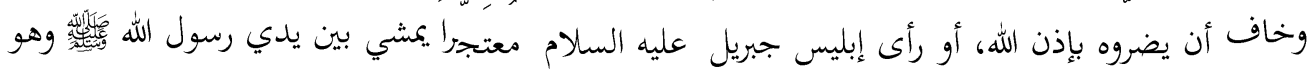

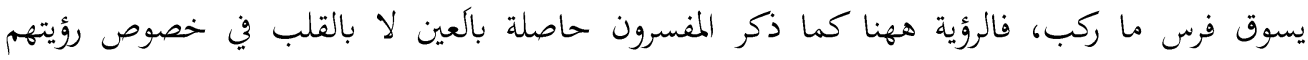

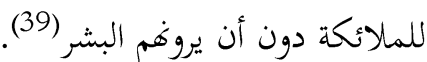

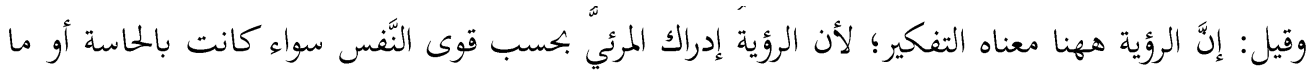

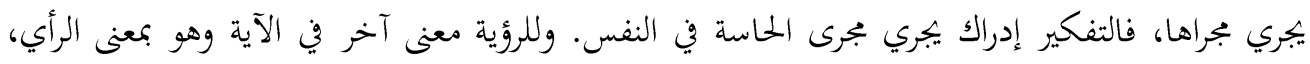

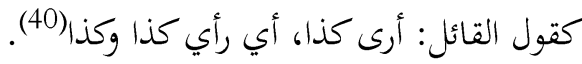

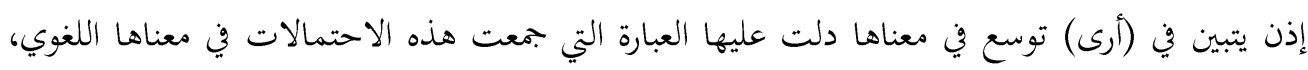

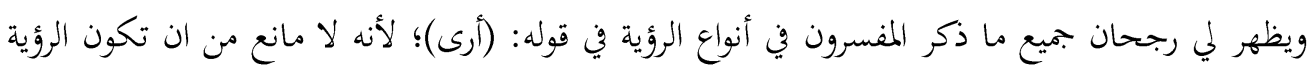
حصلت في القلب والعين والثفكير.

\section{ثالثا: التوسع في معنى (يسمعون)}

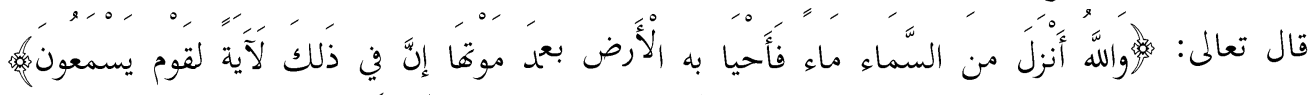
(النحل: 65).

ذكر الصفدي بأن الفعل (يسمعون) بعمنى يقبلون، ويتمل بمعنى السمع الحقيقي، أي: يسمعون القرآن(41).

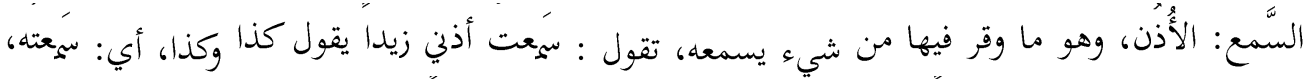

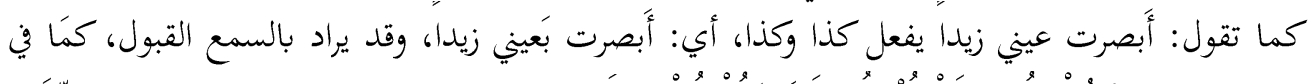

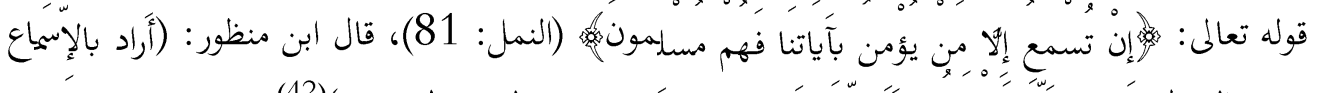

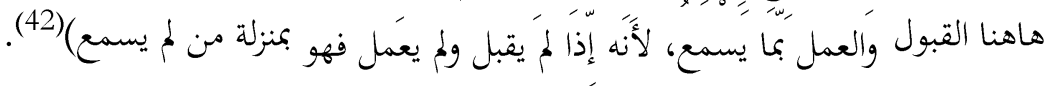


قال المفسرون إنَّ المقصود في قوله: (لقوم يسمعون) سمع القلوب لا سع الأذن، أي ساع اعتبار وتدبر،

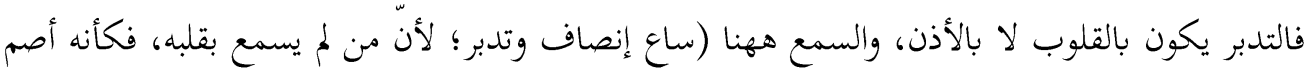
لا يسمع)(43)

وقد يكون السمع بمعنى الفهم والإدراك، فقال ابن كثير: (يسمعون، أَي: يفهمون الكلام ومعناه)(44).

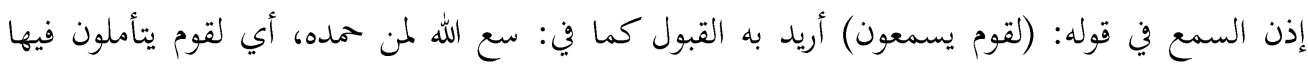
ويعقلون وجه دلالتها ويقبلون مدلولها. ويظهر أن المفسرين أرادو بمعنى السمع في الآية، حقيقة ادراك

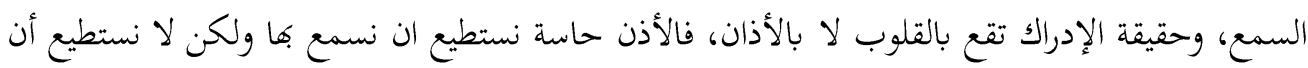

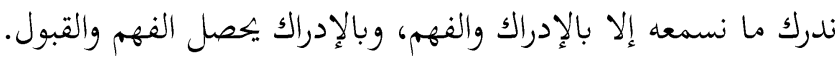

\section{المبحث الثالث: التوسع في معنى فعل الأمر}

\section{التوسع في معنى (انظرنا)}

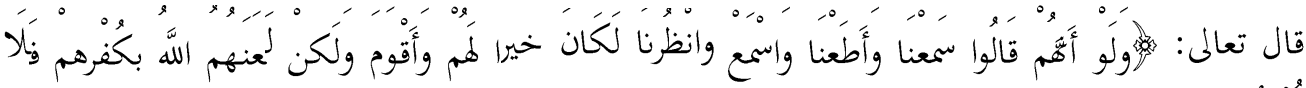

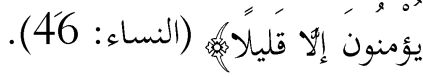
تناؤل الصَفََي نوع آخر من الأفعال وهو توسع معنى فعل الأمر، فالفعل (انظرنا) في الآية الكريمة، فيه توسع في المعنى، فذهب الصفدي في معرض تفسيره إلى أن الفعل (انظرنا) يحتمل بمعنى النظر، أي: أنظر ما نفعل، ويحتمل بمعنى الانتظار، أي: انتظرنا وتمهَّل علينا (45).

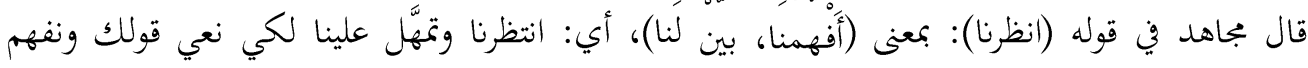

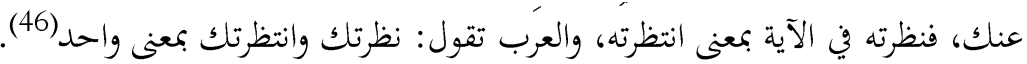

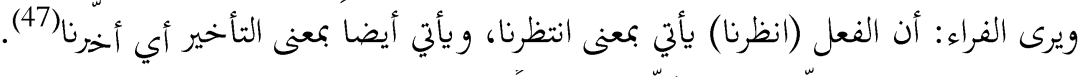

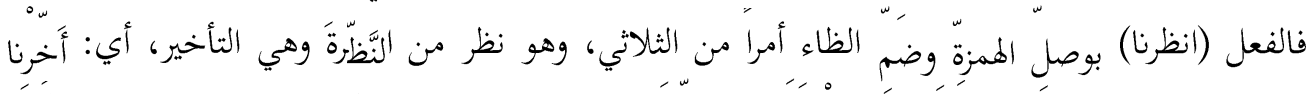

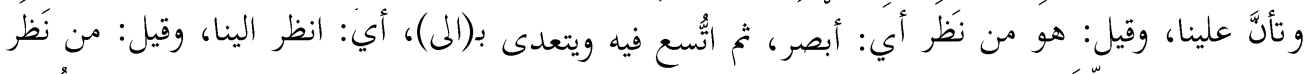

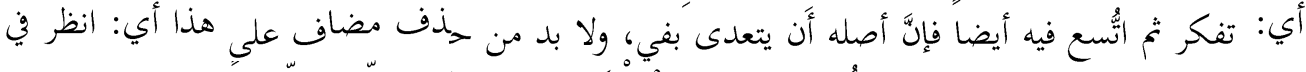

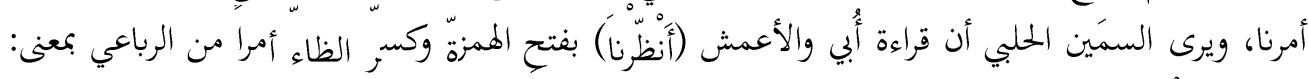

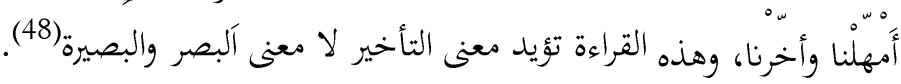


ويظهر مما سبق أن فعل الأمر (انظرنا) لفظ توسع فيه المعنى، واحتملة العبارة الواحدة على عدة معاني

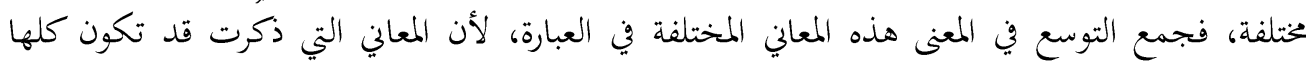
مقصودة في المعنى.

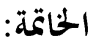

وبعد هذه الرحلة التي ليست بالسهلة في البحث والتنقيب في دراستي لعلل التعبير القرآي، والبحث الطويل

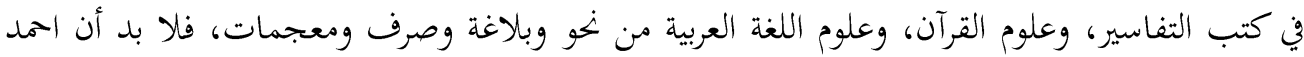

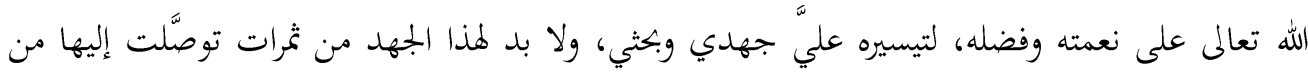
خلال دراستي وبحثي في بجال التعبير القرآين، يمكن أن استخلصها في النتائج الآتية: 1. سار الصفدي في تفسيره على خطى غيره من المفسرين، فلم يكتف بـ بتفسير الآية فقط، تطرّّ إلى امور

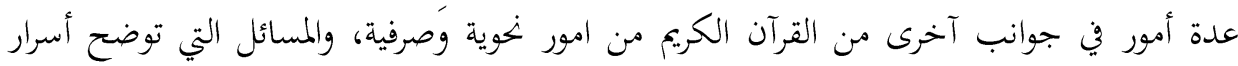
التعبير القرآين. 2. أخذ الصفدي بآراء وعلل من قبله من العلماء ونقل عنهم، ولكن لم ينسب تلك الآراء إلى قائليها في أكثر المواضع التي تناولت القضايا التعبيرية. 3. يتمثل اللفظ القرآي، بقدرة اللفظ الواحد أو العبارة الواحدة على أن تحتمل معاني عدَّة في تعبير

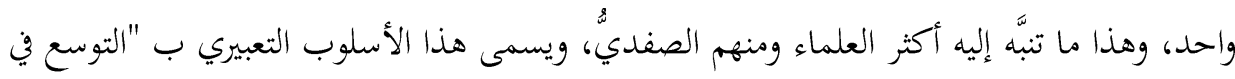

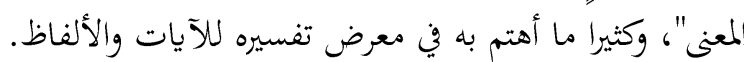

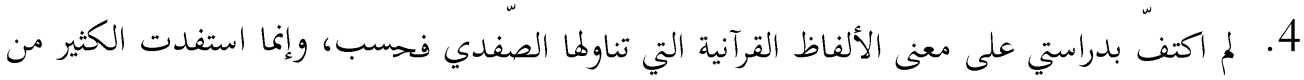

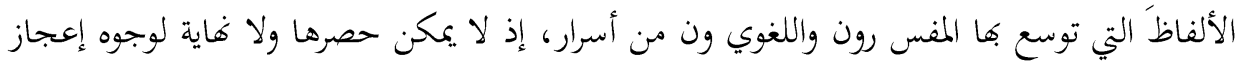
هذا الكتاب المحكم من الله تعالى.

المصادر :

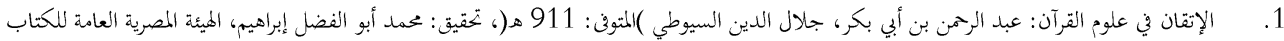

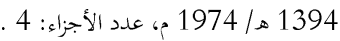
أثر تعدد الإعراب في توسع المعنى عند الزخشري في الكشاف: أسعد عبد العيلم السعدي، (بكث منشور في بحلة كلية الآداب_ جامعة الأنبار، العدد

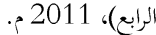
التحرير والتوير: محمد الطاهر بن محمد بن محمد الطاهر بن عاشور التونسي (المتوف: 1393 هـ)، دار النشر: دار سحنون للنشر والتوزيع - تونس - 
5. كشف الأسرار وهتك الأستار: لجمال الدين الصفدي (المتوف: 696 هـ)، تحقيق: بهاء الدين دارتما، الناشر: دار البحوث الإسلامية في تركيا وهو ضمن سلسلة عيون التزاث الإسلامية، الطبعة: 2019 م، عدد الأجزاء: 4.

(1) ينظر :الصحاح ( وسع 1298 / / 3 :)،ومقاييس اللغت(وسع 109 / 6 : )،ولسان العرب( وسع 393 _ 392 / 8 / :)،وتاج العروس(وسع. 325 / 22)

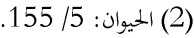

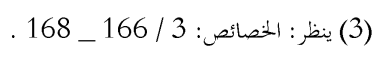

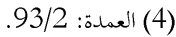

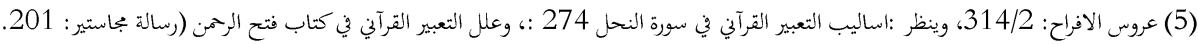

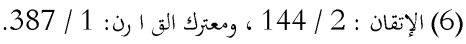

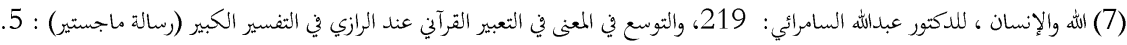
(8) الجملة العربية والمعنى: 163 (8)

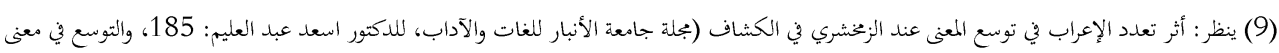

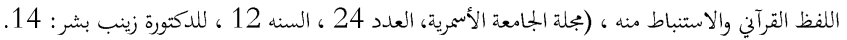

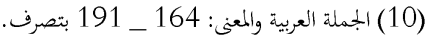

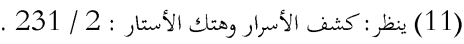

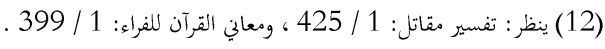

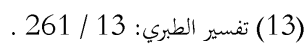

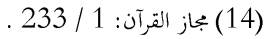

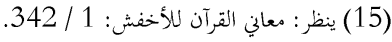

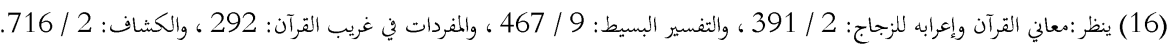

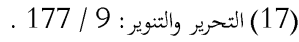

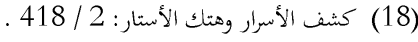

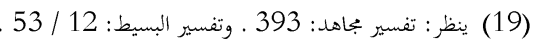

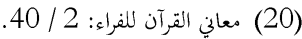

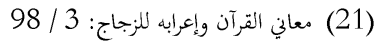
(22) (23) المفردات في غريب القران: 409.

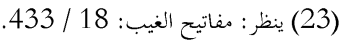

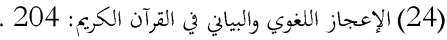

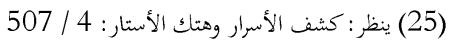

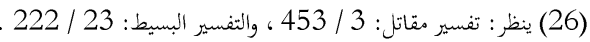

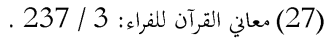

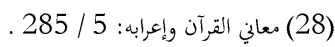

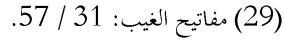

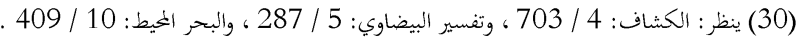

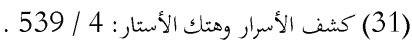

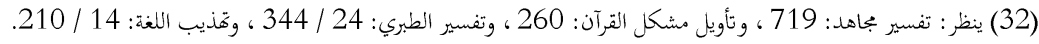

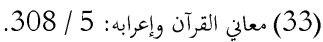

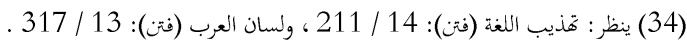


(35) ينظر : كشف الأسرار وهتك الأستار : 2 / 249.

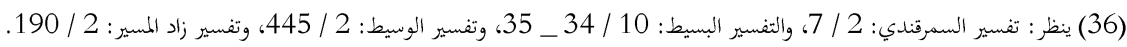

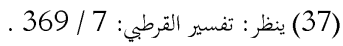

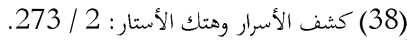

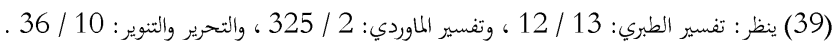

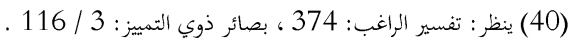

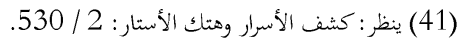

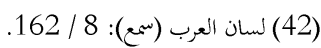

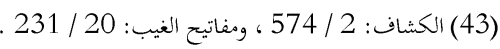

(44) تفسير ابن كثير: 4 / 498 . 4 (43)

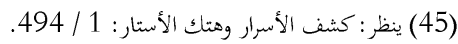

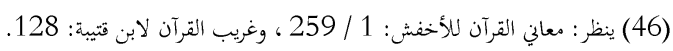

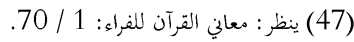

(48) الدر المصون: 52 / 52 (47) 